\title{
Efficient termination of transcription by RNA polymerase I requires the 5' exonuclease Rat1 in yeast
}

\author{
Aziz El Hage, ${ }^{1}$ Michal Koper, ${ }^{2}$ Joanna Kufel, ${ }^{2}$ and David Tollervey ${ }^{1,3}$ \\ ${ }^{1}$ Wellcome Trust Centre for Cell Biology, University of Edinburgh, Edinburgh EH9 3JR, United Kingdom; ${ }^{2}$ Institute of \\ Genetics and Biotechnology, Faculty of Biology, University of Warsaw, 02-106 Warsaw, Poland
}

\begin{abstract}
During transcription termination by RNA polymerase II on protein-coding genes, the nuclear 5' exonuclease Rat1/Xrn2 degrades the nascent transcript downstream from the polyadenylation site and "torpedoes" the polymerase. We report that the activity of Rat1 is also required for efficient termination by RNA polymerase I (Pol I) on the rDNA. In strains lacking catalytically active Rat1 or its cofactor Rai1, Pol I reads through the major, "Reb1-dependent" terminator (T1) but stops downstream at the "fail-safe" terminator (T2) and replication fork barrier (RFB). The absence of both Rat1 and the RFB-binding protein Fob1 increased Pol I read-through of $T 2$ and the $\mathrm{RFB}$. We propose that cotranscriptional cleavage of the pre-rRNA by the endonuclease Rnt1 generates a loading site for the Rat1/Rai1 complex, which then degrades the nascent transcript. When Rat1 catches Pol I, which is predicted to be paused at T1, transcription is terminated.
\end{abstract}

[Keywords: Ribosome synthesis; rRNA synthesis; RNA polymerase I; exonuclease; transcription termination] Supplemental material is available at http://www.genesdev.org.

Received November 14, 2007; revised version accepted February 29, 2008.

Under good growth conditions each Saccharomyces cerevisiae cell will produce $\sim 2000$ mature ribosomes per minute, requiring the synthesis of some $14 \mathrm{Mb}$ of prerRNA and 160,000 ribosomal proteins. The rDNA genes in S. cerevisiae form an array of 150-200 repeats located on chromosome XII, around one-half of which are actively transcribed. The high rate of ribosome synthesis means that these rDNA repeats must each give rise to $>20$ pre-rRNA transcripts per minute. Each rDNA repeat contains the $35 \mathrm{~S}$ gene, transcribed by RNA polymerase I (Pol I), and the intergenic spacer regions (IGS1 and IGS2). The 5S gene, which is independently transcribed by RNA Polymerase III (Pol III), separates IGS1 from IGS2 (see Fig. 1A). IGS1 contains the replication fork barrier (RFB) region extending from +282 to +418 from the $25 \mathrm{~S}$ sequence (see Fig. 2A). Fobl protein binds to the RFB. These establish a DNA-protein structure that blocks DNA replication forks from moving in the opposite direction to the Pol I transcription machinery, preventing their collision (Takeuchi et al. 2003; Huang et al. 2006).

Analyses of Pol I transcription performed in vitro and in vivo in yeast showed that $\sim 90 \%$ of transcripts terminate at the "Reb1-dependent" or "primary" terminator (herein referred to as T1) (see Fig. 2A). This is located at a position $\sim 93$ nucleotides (nt) downstream from the $3^{\prime}$

${ }^{3}$ Corresponding author.

E-MAIL d.tollervey@ed.ac.uk; FAX 44-131-650-7040.

Article is online at http://www.genesdev.org/cgi/doi/10.1101/gad.463708. end of the $25 \mathrm{~S}$ sequence in the $3^{\prime}$-external transcribed spacer (3'-ETS) (Lang and Reeder 1993; Reeder and Lang 1994, 1997; Prescott et al. 2004). Approximately 10\% of Pol I molecules read through T1 and stop at the downstream "fail-safe" terminator (herein referred to as T2) (see Fig. 2A). T2 was initially reported to lie at +210 from the 25S sequence (van der Sande et al. 1989), but subsequent analyses mapped it close to around position +250 (Reeder et al. 1999).

At $\mathrm{T} 1$, termination occurs $12-20 \mathrm{nt}$ upstream of the binding site for the Reb1 protein, within a T-rich element that encodes the last 10-12 nt of the terminated transcript (Reeder and Lang 1997). In the mouse, the Reb1 homolog TTF1 cooperates with a transcript release factor called PTRF in conjunction with the T-rich DNA sequence to induce transcription termination and dissociate Pol I and the transcript from the template DNA (Jansa and Grummt 1999). No equivalent transcript release factor has been identified in yeast, but in vitro and in vivo data suggested the existence of such factors (Reeder and Lang 1997; Tschochne and Milkereit 1997; Jansa and Grummt 1999). At T2 in yeast, termination also occurs at or close to an extended, highly T-rich element (Reeder et al. 1999), but the specific protein factors involved have not yet been identified.

Deletion of the RPA12 gene, which encodes a small subunit of Pol I, leads to increased read-through of T1 (Prescott et al. 2004). Rpa12 is homologous with the small RNA polymerase II (Pol II) subunit Rpb9, which is 
Figure 1. Rat1 depletion leads to defects in 5.8S rRNA processing. (A) Schematic of an rDNA repeat in $S$. cerevisiae showing the $5^{\prime}$ processing of $5.8 \mathrm{~S}$ rRNA. The rDNA repeat includes the $35 \mathrm{~S}$ pre-RNA gene, which is transcribed by Pol I and processed to mature 18S, 5.8S, and 25S rRNAs. (Pro) Pol I promoter. The $35 \mathrm{~S}$ genes are separated by IGS1 and IGS2 and the 5S rRNA gene, which is transcribed by Pol III in the opposite direction (indicated by arrows). The pre-rRNA is cleaved at site $\mathrm{A}_{3}$ by the endonuclease RNase MRP (Lygerou et al. 1996) and then processed by Rat1/Rail to site $\mathrm{B}_{1 \mathrm{~S}}$, the $5^{\prime}$ end of the $5.8 \mathrm{~S}_{\mathrm{S}}$ rRNA. A distinct minor pathway, which is independent of Rat 1 activity, generates the $5^{\prime}$ end of the longer $5.8 \mathrm{~S}_{\mathrm{L}}$ rRNA at site $\mathrm{B}_{1 \mathrm{~L}}$. Processing in ITS2 generates the $3^{\prime}$ end of both $5.8 \mathrm{~S}$ species at site E. $(B)$ Rat 1 mRNA depletion. Total RNA was extracted from $P_{M E T 3}-R A T 1$ and $P_{M E T 3}-R A T 1, \quad x r n 1 \Delta$ strains grown at $30^{\circ} \mathrm{C}$ in the absence of methionine (0-h samples) or in the presence of $5 \mathrm{mM}$ methionine for the times indicated and resolved on a $1.2 \%$ agarose/ glyoxal gel. RAT1 mRNA was detected with a random primed probe (see Materials and Methods; Supplemental Table S2). (Bottom panel) As a control, the abundant cytoplasmic SCR1 RNA was detected with oligonucleotide SCR1 (see Supplemental Table S2). (C) Northern analysis of 5.8S rRNA maturation. RNAs extracted as above were resolved on an $8 \%$ polyacrylamide/urea gel. Mature $5.8 \mathrm{~S}_{\mathrm{S}}$ and $5.8 \mathrm{~S}_{\mathrm{L}}$ rRNAs and extended pre-5.8S species $\left(\mathrm{A}_{3}\right)$ were detected with probe 017 (see Supplemental Table S2). The top panel $\left(\mathrm{A}_{3}\right)$ shows a longer exposure than the middle panel $\left(5.8 \mathrm{~S}_{\mathrm{S}}\right.$ and $5.8 \mathrm{~S}_{\mathrm{L}}$ ). (Bottom panel) As a control, the abundant cytoplasmic SCR1 RNA was detected with oligonucleotide SCR1. (D) Primer extension analysis of $5.8 \mathrm{~S}$ rRNA maturation. RNA was extracted from wild-type and $P_{M E T 3}-R A T 1$, xrn1 $\Delta$ strains as above and from rat1-1, xrn1 $\Delta$ strain grown at $25^{\circ} \mathrm{C}$ and following transfer for $2 \mathrm{~h}$ to $37^{\circ} \mathrm{C}$. Primer extension products using oligonucleotide 017 were resolved on a $6 \%$ polyacrylamide/urea gel. The primer extension stops at $\mathrm{B}_{\mathrm{L}}$ and $\mathrm{B} 1_{\mathrm{S}}$ represent the $5^{\prime}$ ends of the mature $5.8 \mathrm{~S}_{\mathrm{S}}$ and $5.8 \mathrm{~S}_{\mathrm{L}}$ rRNAs, respectively. The bottom panel shows a shorter exposure than the top panel.

similarly implicated in transcription termination (Awrey et al. 1997). Inactivation of the chromatin remodeling ATPases Chd1, Isw1, and Isw2 also caused defects in transcription termination by both Pol I and Pol II (Alen et al. 2002; Jones et al. 2007). These observations pointed to similarities in the termination of transcription by Pol I and Pol II. Efficient transcription termination on mRNA genes requires the catalytic activity of the highly processive nuclear $5^{\prime}-3^{\prime}$ exonuclease Rat1 (Xrn2 in humans) (Kim et al. 2004; West et al. 2004; Luo et al. 2006; Kaneko et al. 2007). Cotranscriptional cleavage by the polyadenylation machinery at the $3^{\prime}$ end of the pre-mRNA allows Rat 1 to attack the free $5^{\prime}$ end of the downstream cleavage product. When Rat1 catches up with Pol II the transcription terminates. Rat 1 is thus said to "torpedo" the polymerase.

Xrn 1, the second, mainly cytoplasmic, 5'-3' exonuclease in yeast, can degrade many $5^{\prime}$-extended RNAs that would otherwise accumulate in the absence of Rat1, in- cluding $5^{\prime}$-extended pre-5.8S and 25S pre-rRNAs (Henry et al. 1994; Geerlings et al. 2000). Xrn1 is detected exclusively in the cytoplasm of wild-type cells, and artificial relocation of Xrn1 to the nucleus, by fusion with a strong nuclear localization signal, suppresses the lethality of the rat1-1 mutation (Johnson 1997; Luo et al. 2006). This implies that there normally can be little if any nuclear Xrn1, even in the absence of fully functional Rat1. Moreover, Xrn1 cannot replace Rat1 for its role in mRNA transcription termination in the rat1-1 mutant even when targeted to the nucleus (Luo et al. 2006).

During Pol I transcription, the RNase III-like endonuclease Rntl cleaves the nascent pre-rRNA across a stem-loop structure within the $3^{\prime}$-ETS, at positions +14 / 15 and $+49 / 50$ relative to the $3^{\prime}$ end of the 25S rRNA sequence (see Fig. 2A; Kufel et al. 1999). Rnt1 was detected at the site of rRNA transcription (Henras et al. 2004), and can interact physically with Pol I subunits including Rpa12 (Catala et al. 2008). Moreover, loss of 


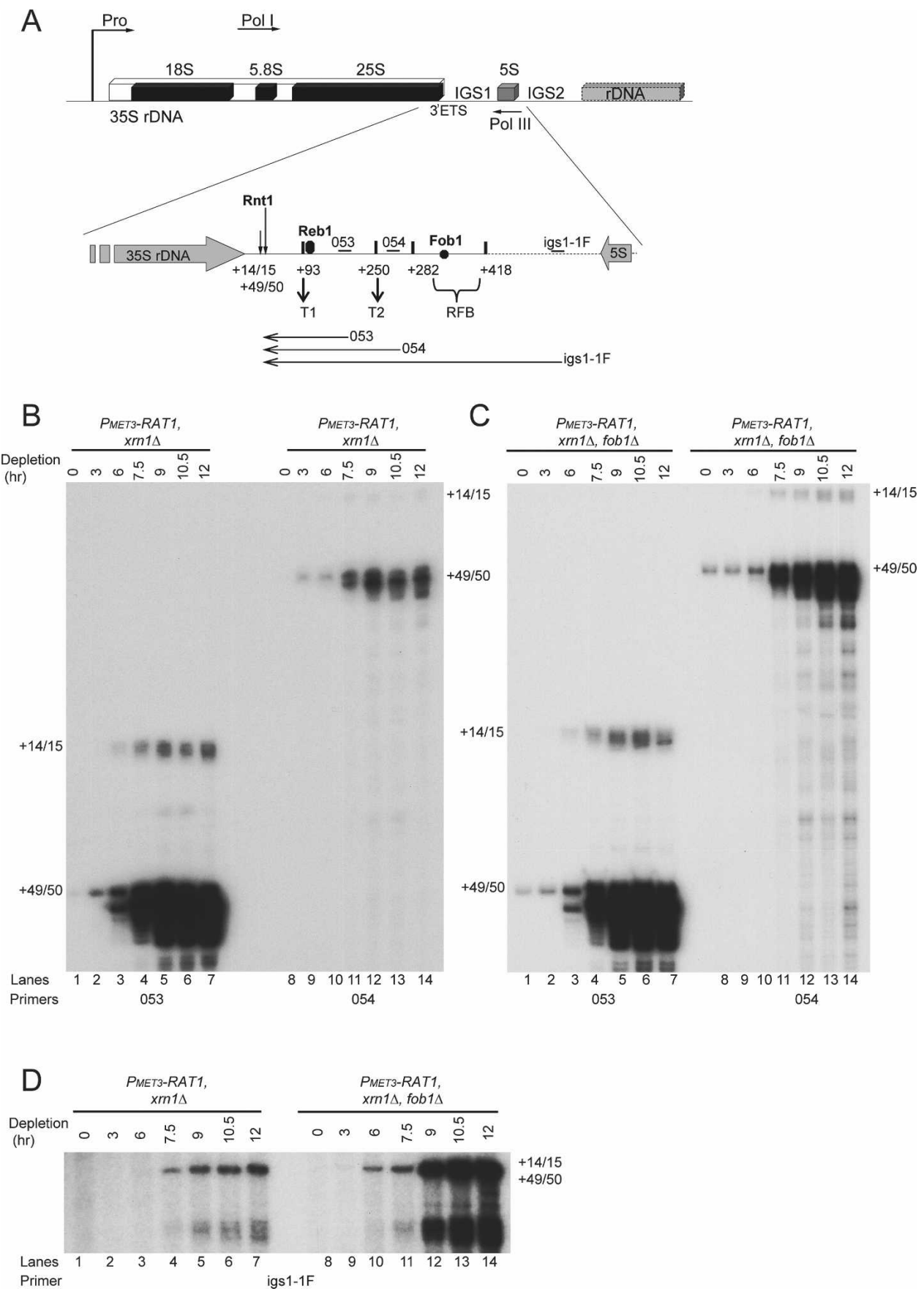

Figure 2. The $5^{\prime}$ ends of IGS1 transcripts map to the Rnt 1 cleavage sites at $+14 / 15$ and $+49 / 50$ in the $3^{\prime}$-ETS. $(A)$ Schematic of an rDNA repeat in $S$. cerevisiae (as in Fig. 1A). Rnt1 cleaves the 35 S pre-rRNA in the 3'-ETS in IGS1 at $+14 / 15$ and $+49 / 50$ relative to the 3 ' end of the 25S rRNA sequence. Pol I transcription predominantly terminates at the "Reb1-dependent" terminator (T1) located at approximately $+93 \mathrm{nt}$. Reb1 binds a few nucleotides downstream from +93. A "fail-safe" terminator (T2) is located at approximately +250 , followed by the RFB, which binds Fob1 and extends from +282 to +418 . Oligonucleotides used (see also Supplemental Table S2) are indicated by small horizontal bars above the rDNA. Probe 053 is located between T1 and T2 at position +180 , probe 054 is located between T2 and the RFB at +264 , and probe igs $1-1 \mathrm{~F}$ is located between the RFB and the 5 S rRNA gene at +832 . Horizontal arrows below the rDNA indicate the RNA species detected by primer extensions. $(B-D)$ RNAs extracted from strains $P_{M E T 3}-R A T 1$, xrn1 $1 \Delta$ and

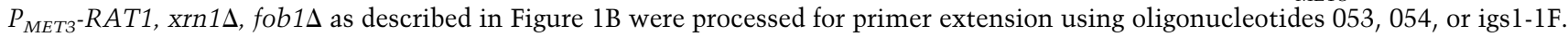
Products were resolved on $6 \%$ polyacrylamide/urea gels. Primer extension stops at $+14 / 15$ and $+49 / 50$ are labeled.

Rnt1 activity influences rDNA transcription and chromatin structure (Catala et al. 2008), consistent with cotranscriptional activity. A rnt $1 \Delta$ strain showed increased read-through of $\mathrm{T} 1$ with most Pol I stopping at T2 (Reeder et al. 1999; Prescott et al. 2004), and readthrough transcripts extending to $\mathrm{T} 2$ were also detected 
in rnt1-ts strains (Catala et al. 2008), indicating that cotranscriptional cleavage is important for efficient termination at T1. Rnt1 cleavage generates products with $5^{\prime}-$ monophosphate termini, the preferred substrates for Rat1 (Stevens and Poole 1995), which was reported previously to participate in the degradation of the 3 '-cleavage product (Kufel et al. 1999), raising the interesting possibility that Rat1 might also "torpedo" Pol I during transcription termination.

Here we show that Ratl plays a role in Pol I transcription termination. When Rat 1 is absent from the cells, Pol I fails to efficiently terminate at $\mathrm{T} 1$ but mainly stops at $\mathrm{T} 2$ and at the RFB. In the absence of both Rat 1 and Fob1, read-through of $\mathrm{T} 2$ and the RFB was substantially increased. We further show that the catalytic activity of Rat1 is essential for Pol I transcription termination to occur, suggesting that Rat1 "torpedoes" the polymerase on rDNA genes during termination, as is the case for Pol II on mRNA-coding genes.

\section{Results}

Rat1 and Rai1, but not Xrn1, contribute to productive 5.8S rRNA maturation

The rat1-1 mutation is temperature-sensitive lethal and leads to the accumulation of 5 '-extended forms of the 5.8S rRNA at nonpermissive temperatures (Amberg et al. 1992). However, very little of the extended RNA was detected in the rat1-1 single mutant (Henry et al. 1994). This apparently poor penetrance of the rat1-1 mutation led us to assess whether a stronger phenotype could be generated by placing the RAT1 gene under the control of a conditional MET3 promoter. Yeast cells carrying $P_{M E T 3}-R A T 1$ were pregrown in SD medium lacking methionine then shifted to $\mathrm{SD}+5 \mathrm{mM}$ methionine to inhibit RAT1 expression. The levels of RAT1 mRNA were substantially reduced $3 \mathrm{~h}$ after methionine addition (Fig. 1B, lanes 1-6).

Maturation by Rat 1 is required to form the $5^{\prime}$ end of the major, short form of $5.8 \mathrm{~S}$ rRNA $\left(5.8 \mathrm{~S}_{\mathrm{S}}\right)$ but is not required for formation of the longer $5.8 \mathrm{~S}_{\mathrm{L}}$ rRNA (Henry et al. 1994). In the absence of functional Rat1, synthesis of $5.8 \mathrm{~S}_{\mathrm{L}}$ is therefore favored. Northern analysis (Fig. 1C, lanes 1-6) using a probe that hybridizes to the 5.8S rRNA (probe 017) (Fig. 1A) showed that the ratio of $5.8 \mathrm{~S}_{\mathrm{S}}$ to $5.8 \mathrm{~S}_{\mathrm{L}}$ was reduced in the $P_{M E T 3}-R A T 1$ strain, commencing $9 \mathrm{~h}$ after methionine addition, indicating efficient Rat 1 depletion. The 5 '-extended forms of the 5.8S rRNA were not clearly accumulated in the $P_{\text {MET3 }}-R A T 1$ single mutant strain, whereas species extended to the $\mathrm{A}_{3}$ cleavage site accumulated strongly in strains also lacking the 5' exonuclease Xrn1 (Fig. 1C, top panels, cf. lanes 1-6 and 7-13). Xrn1 is exclusively detected in the cytoplasm (Johnson 1997) and, consistent with this, the presence or absence of Xrn1 did not affect the ratio between the $5.8 \mathrm{~S}_{\mathrm{S}}$ and $5.8 \mathrm{~S}_{\mathrm{L}}$ species (Fig. 1C, middle panels, cf. lanes 1-6 and 7-13).

Rat1 is associated with a cofactor, Rail (Xue et al. 2000), that was reported to enhance the activity of Rat1 in 5.8S rRNA processing and in transcription termination by Pol II (Xue et al. 2000; Kim et al. 2004). The absence of Rail modestly enhanced accumulation of 5 'extended 5.8S rRNA prior to depletion of Rat1 (0-h sample) in the $P_{M E T 3}-R A T 1$, xrn1s background (Supplemental Fig. S1A, lane 3). However, the rai1s single mutant strongly enhanced the $5.8 \mathrm{~S}_{\mathrm{L}}$ to $5.8 \mathrm{~S}_{\mathrm{S}}$ ratio, without clear accumulation of 5 '-extended species (Supplemental Fig. S1A, lane 2), and the absence of Rail enhanced the deficit in the $5.8 \mathrm{~S}_{\mathrm{L}}$ to $5.8 \mathrm{~S}_{\mathrm{S}}$ ratio seen on Rat depletion (Supplemental Fig. S1B, cf. lanes 1-5 and 8-12). These data are consistent with a "window of opportunity" for processing by Rat1 from $\mathrm{A}_{3}$ to $\mathrm{B}_{1 \mathrm{~S}}$ to generate $5.8 \mathrm{~S}_{\mathrm{S}}$ (Fig. 1A). In the absence of Rail, Rat1 may load more slowly or act less processively, favoring the alternative processing at $\mathrm{B}_{1 \mathrm{~L}}$. A similar situation occurs in the absence of Rat1 where Xrn1 does not contribute to productive

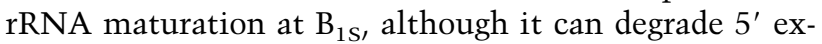
tensions present on the $5.8 \mathrm{~S}$ precursors (Fig. 1C, cf. lanes 1-6 and 7-13).

Rat1 is also responsible for $5^{\prime}$ maturation of the $25 \mathrm{~S}$ rRNA (Geerlings et al. 2000). Primer extension with a primer within the mature 25S rRNA (probe 007) (Fig. 1A) revealed strong accumulation of the $26 \mathrm{~S}$ pre-rRNA, which extends to the $\mathrm{C}_{2}$ cleavage site within ITS2 (internal transcribed spacer 2), in the $P_{\text {MET3 }}$ RAT1, xrn1D strain following methionine addition (data not shown). Comparison of the $P_{M E T 3}-R A T 1, x r n 1 \Delta$ and rat1-1, xrn1 strains (Fig. 1D) revealed stronger accumulation of pre-5.8S and $5.8 \mathrm{~S}_{\mathrm{L}}$ in the $P_{\text {MET3 }}-R A T 1$, xrn1 $1 \Delta$ strain after $12 \mathrm{~h}$ of depletion (Fig. 1D, cf. lanes 2-6 and 7,8). $P_{\text {MET3 }}-R A T 1$ strains were therefore used for further analyses.

\section{Transcripts from IGS1 are stabilized in the absence of Rat1 and Xrn1}

If Rat1 plays a role in Pol I transcription termination then its depletion should lead to increased transcription extending beyond T1 into IGS1 (see Fig. 2A). To assess this, we initially performed primer extension analyses using primers complementary to sequences located downstream from the Rntl cleavage sites beyond the major T1 terminator. Probe 053 is located between T1 and $\mathrm{T} 2$, probe 054 is located between $\mathrm{T} 2$ and the RFB, and probe igs $1-1 \mathrm{~F}$ is located between the RFB and the $5 \mathrm{~S}$ gene (Fig. 2A). Primer extension analyses were performed on RNA recovered from $P_{M E T 3}-R A T 1$ strains before and during Ratl depletion. As the read-through transcripts are degraded by Xrn1 in the $P_{M E T 3}-R A T 1$ strain (see Supplemental Fig. S2), all of the following analyses were performed in xrn1s background. Probes 053 and 054 showed that extended transcripts accumulate progressively during Rat1 depletion, commencing $3 \mathrm{~h}$ after methionine addition (Fig. 2B). These have 5' ends corresponding to the reported sites of Rnt1 cleavage sites at $+14 / 15$ or $+49 / 50$ (Kufel et al. 1999), with the predominant stop at $+49 / 50$ (Fig. $2 B$ ).

To assess whether the RFB also acts as a Pol I terminator, the gene encoding the RFB-binding protein Fob1 was deleted in the $P_{M E T 3}-R A T 1$, xrn1s double mutant strain (Fig. 2C,D). The absence of both Rat1 and Fob1 lead to an increase in the levels of all RNAs that extend 
through T2 (probe 054) (Fig. 2, cf. B and C, lanes 8-14) or both T2 and the RFB (probe igs1-1F) (Fig. 2D, cf. lanes 1-7 and $8-14)$. The species detected with probe igs 1-1F also have a size consistent with $5^{\prime}$ ends at the Rntl cleavage sites, but the products are too long (783/818 nt) for these sites to be clearly resolved (Fig. 2D). Additional heterogeneous stops detected with probe igs1-1F (Fig. 2D, lanes $8-14)$ correspond to the approximate position of T2 and may represent premature primer extension stops due to the presence of the poly $(\mathrm{U})$ tracts in this region.

These data indicate that during Rat 1 depletion in the absence of Xrn1, RNAs accumulate that extend from the sites of cotranscriptional Rntl cleavage in IGS1 to beyond the major T1 terminator. The additional loss of Fob1 increased read-through of both $\mathrm{T} 2$ and the RFB, indicating that the RFB acts as an additional transcription terminator.

In order to analyze further the RNA species that accumulate during Ratl depletion, we performed Northern analyses using primers 053, 054, and igs1-0F, which hybridizes at the $3^{\prime}$ end of IGS1 (Fig. 3A). Progressive accumulation of IGS transcripts was visible in the $P_{\text {MET3- }}$ RAT1, xrn $1 \Delta$ double mutant strain commencing $3 \mathrm{~h}$ after methionine addition (Fig. 3B-D, lanes 1-7). Using primer 053, the major transcripts detected ranged from $~ 160$ to $\sim 300 \mathrm{nt}$ (Fig. 3B, lanes 1-7). We labeled these species 1-3.
Lower levels of longer transcripts were detected over $\sim 400 \mathrm{nt}$ in length (species labeled 4). The $5^{\prime}$ ends of the transcripts predominantly lie at the major Rntl cleavage site at $+49 / 50$ (see Fig. 2), so the $3^{\prime}$ ends of the corresponding RNAs detected by Northern hybridization lie at positions $50 \mathrm{nt}$ further into IGS1 relative to the $3^{\prime}$ end of the $25 \mathrm{~S}$ sequence. The major RNA species accumulated following Rat1 depletion would therefore be consistent with termination around $\mathrm{T} 2(+250$, species 1 and 2 ) and the RFB (+350, species 3) (see also Fig. 3A, horizontal arrows).

In contrast to species 1 and 2 , the longer transcripts (species 4) were detected also by primers 054 and igs1-0F (Fig. 3C,D, lanes 1-7), showing that these extend through T1, T2, and the RFB, as expected (see also Fig. 3A, horizontal arrows). Species 2, which from their gel mobility (over $\sim 200 \mathrm{nt}$ ) would be expected to extend beyond the position of oligo 054 downstream from $\mathrm{T} 2$, were detected with probe 053 but not probe 054 (Fig. 3, cf. B and C, lanes 1-7). Pol I can undergo iterative slippage at poly(dT) coding sequences, such as those located at $\mathrm{T} 2$, leading to addition of nontemplated $3^{\prime}$ poly $(\mathrm{U})$ tracts in vitro (Jeong et al. 1996). This strongly suggests that transcripts 2 terminate around $\mathrm{T} 2$ but have been 3 '-extended with poly(U).

We conclude that IGS1 transcripts accumulated in the absence of Rat 1 and Xrn1 predominantly extend through

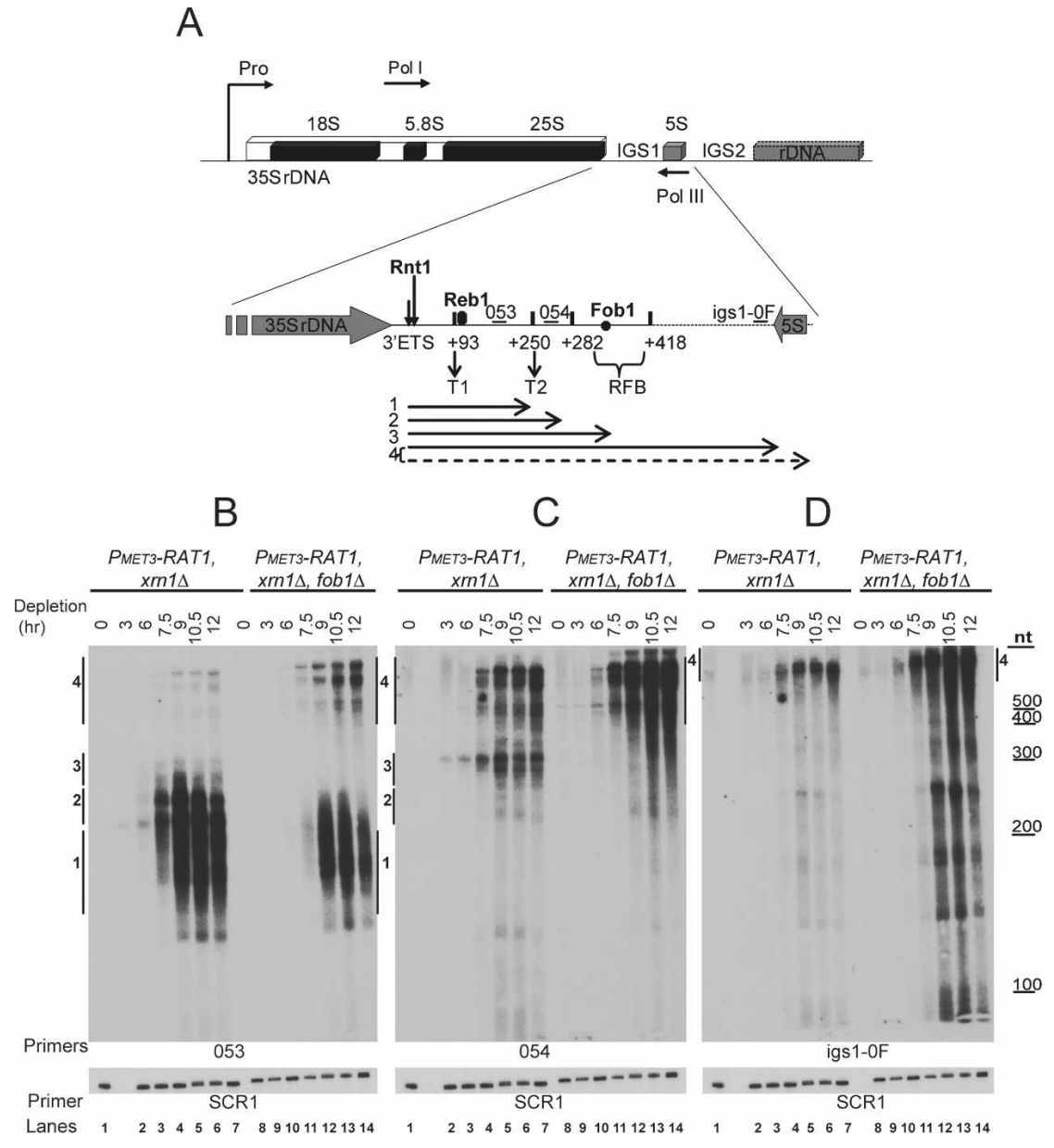

Figure 3. RNAs transcribed from the IGS1 region accumulate when Rat1 and Xrn1 are absent. (A) Schematic of an rDNA repeat in $S$. cerevisiae (as in Fig. 2A). Oligonucleotides used (see also Supplemental Table S2) are indicated by small horizontal bars above the rDNA. Primers 053 and 054 were as in Figure 2A. Primer igs1-0F hybridizes to IGS1 immediately upstream of the $5 \mathrm{~S}$ gene at +1054 relative to the $3^{\prime}$ end of the $25 \mathrm{~S}$ rRNA sequence. Horizontal arrows below the rDNA indicate the RNA species (labeled 1-4) detected by Northern hybridizations. $(B-D)$ Northern analyses. RNAs were extracted from the strains $P_{M E T 3}-R A T 1$, $\mathrm{xrn1 \Delta}$, and $P_{M E T 3}-R A T 1, \mathrm{xrn} 1 \Delta$, fob1 $1 \Delta$ as described for Figure 1B. Total RNA and an RNA ladder (RNA Century, Ambion) were resolved on an $8 \%$ polyacrylamide/urea gel. The same filter was probed sequentially with oligonucleotides $053(B), 054$ $(C)$, igs1-0F $(D)$, and SCR1. 
$\mathrm{T} 1$ to the region that encompasses $\mathrm{T} 2$ and the RFB, with lower levels of species extending beyond the RFB.

In the $P_{\text {MET3 }}-R A T 1, x r n 1 \Delta$, fob1 $1 \Delta$ triple mutant strain, the $\sim 300$-nt bands predicted to arise from termination at the RFB were absent (species 3 in Fig. 3B,C, cf. lanes 1-7 and 8-14), and species corresponding to termination around T2 were greatly reduced in length and abundance (species 1 and 2 in Fig. 3B, cf. lanes 1-7 and 8-14). This was accompanied by a large accumulation of longer transcripts extending through the IGS1 region (species 4 in Fig. 3B-D, lanes 8-14). Analyses on agarose gels revealed that these long species have heterogeneous $3^{\prime}$ ends, mainly located between the $3^{\prime}$ end of IGS1 and the start of IGS2 (Supplemental Fig. S3). A very low level of transcripts extended through all of IGS1 and IGS2 to a position $\sim 300 \mathrm{nt}$ upstream of the transcription initiation site of the downstream 35S gene (van der Sande et al. 1989).

These data show that the RFB acts as a terminator for Pol I molecules that read through both $\mathrm{T} 1$ and $\mathrm{T} 2$, with additional terminators located mainly between the $3^{\prime}$ end of IGS1 and the beginning of IGS2.

To assess the requirement for Rail in degradation of the IGS transcripts, we analyzed total RNAs from wildtype, rai1s, and $P_{M E T 3}-R A T 1, x r n 1 \Delta$, rai11 strains. Only modest effects of rai1 $\Delta$ were detected on the accumulation of the IGS1 transcripts (Supplemental Fig. S1C).

\section{Rat1 associates with the 3 '-ETS region of the rDNA}

Previous chromatin immunoprecipitation (ChIP) analyses detected Rat1/Xrn2 downstream from the poly(A) site on mRNA-coding genes (Kim et al. 2004; Luo et al. 2006; Kaneko et al. 2007), consistent with its role in Pol
II termination. To assess whether Ratl functions directly in Pol I termination, we monitored the distribution of Rat1 over the rDNA by ChIP (Fig. 4A). Two peaks of Rat1 occupancy were localized to distinct regions, at the $5^{\prime}$ end of the $35 \mathrm{~S}$ pre-rRNA-coding region and over the region of IGS1 that includes the T1, T2, and RFB terminators. In contrast, no association of Xrn1-TAP was detected under the same conditions, as expected from its reported cytoplasmic localization (Johnson 1997). As positive controls, two mRNA coding genes ADH1 (Fig. 4B) and CYC1 (data not shown) were also analyzed. $A D H 1$ gave a strong Rat1-TAP ChIP signal, whereas $C Y C 1$ gene gave a lower signal, but higher than that seen for the rDNA IGS1 ChIP. These data are consistent with recruitment of Rat1 to transcripts derived from the 3'ETS region of the $35 \mathrm{~S}$ gene. The association with other regions of the rDNA may reflect the recruitment of Rat1 to other sites on the pre-rRNA. In contrast to Rat1, no ChIP signal above the background was detected for Rnt1TAP (data not shown). The available data indicate that Rnt1 does bind to the pre-rRNA cotranscriptionally and is present at the site of transcription (Henras et al. 2004), but its transient association with the nascent transcript apparently is not captured by cross-linking in ChIP analyses.

\section{Pol I termination is impaired when Rat1 or the cofactor Rail is absent}

To determine whether Pol I termination is impaired in strains lacking Rat1, we performed transcription run-on analyses (TRO) using a previously described set of M13 phage probes (Prescott et al. 2004). These cover the IGS1
A

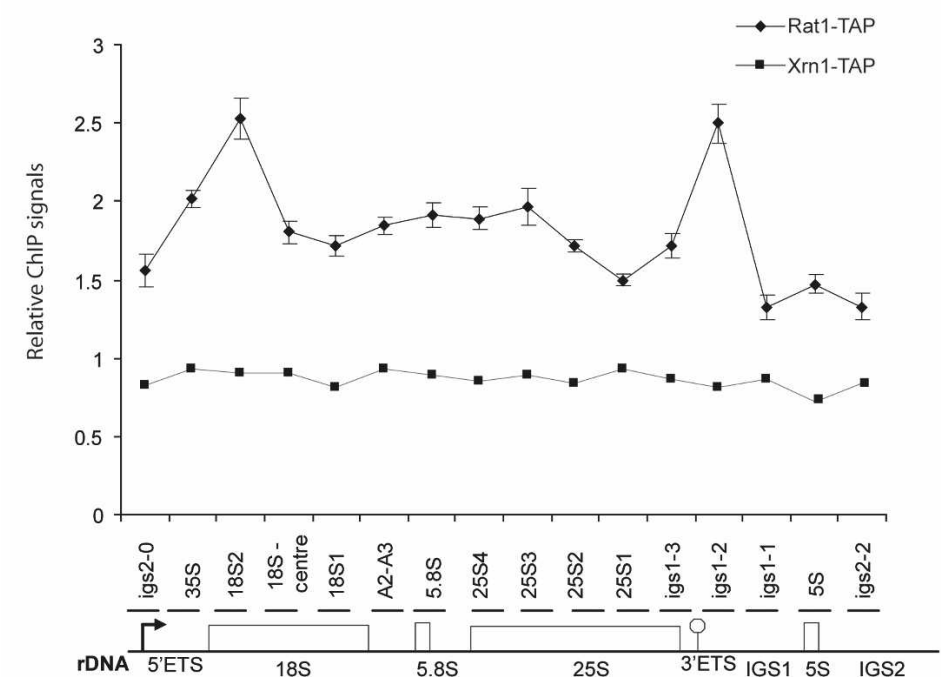

B

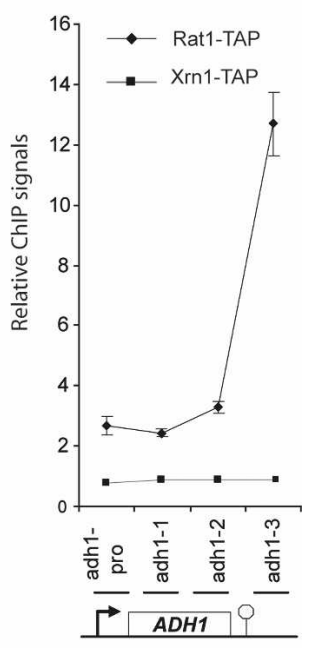

Figure 4. Rat1 but not Xrn1 can be cross-linked to the rDNA. ChIP analyses were performed for Rat1-TAP and Xrn1-TAP over the rDNA $(A)$ and $A D H 1(B)$. The promoter is depicted by an arrow. The "Reb1-dependent" terminator T1 (rDNA) and the poly(A) site $(A D H 1)$ are represented by lollipops. Horizontal bars above the rDNA or ADH1 denote the locations of products amplified by real-time PCR (see also Supplemental Table S3). QPCR values were corrected for background as described in the Materials and Methods. A value of 1 (Y-axis) indicates no signal above background. The mean of six independent experiments is shown with standard error for Rat1-TAP. The mean of two independent experiments is shown for Xrn1-TAP. 
region from the $3^{\prime}$ end of $25 \mathrm{~S}$ to $151 \mathrm{nt}$ downstream from the RFB (probes r2-r7) (Fig. 5A). In wild-type cells, the TRO signal significantly declines immediately after T1 (probe r3), with background levels further downstream (probes r4-r7) (Fig. 5B-E). In $P_{M E T 3}-R A T 1$ cells grown under permissive conditions, the signals were similar to the wild type (0-h samples in Fig. 5B,C), whereas cells depleted for Rat1 (12-h samples in Fig. 5B,C) showed strongly increased TRO signals over the region extending from $\mathrm{T} 1$ to the RFB (probes $\mathrm{r} 3-\mathrm{r} 5$ ) with a smaller increase over the RFB region ( $\mathrm{r} 6$ and $\mathrm{r} 7$ ). Cells lacking the Rat1 cofactor Rail also showed clearly increased readthrough of T1 (Fig. 5D,E). In contrast, seven TRO replicates using the xrn1s strain failed to show any significant read-through of T1 (data not shown). Analyses of strains lacking Fob1 showed that there was no detectable read-through of $\mathrm{T} 1$ in the fob1s single mutant, but an increased TRO signal was observed over the RFB region (r6 and r7) in $P_{\text {MET3 }}-$ RAT1, fob1 1 relative to $P_{\text {MET3 }}-R A T 1$ after $12 \mathrm{~h}$ of depletion (data not shown).
We conclude that the efficiency of Pol I transcription termination at the $\mathrm{T} 1$ terminator is reduced when Rat 1 or the cofactor Rail is absent. The transcription readthrough in the rai1s strain is in contrast to the lack of clear RNA stabilization (Supplemental Fig. S1C), confirming that the failure in RNA degradation is not causal in the termination defect. These data resemble the effects of Rat1, Rail, and Xrn1 on 5' processing of 5.8S (Fig. 1). Rat 1 and Rail are required for efficient termination, whereas Xrn1 can degrade the IGS transcripts that would otherwise accumulate in the absence of Ratl but does not participate in productive termination.

Pol I accumulates over the IGS1 region in the absence of Rat1

To confirm that the TRO data reflect transcription by RNA Pol I, we also monitored Pol I distribution over the IGS region in the presence or absence of Ratl by ChIP using an epitope-tagged Pol I subunit (Rpa34-13MYC) (Fig. 6) or an-
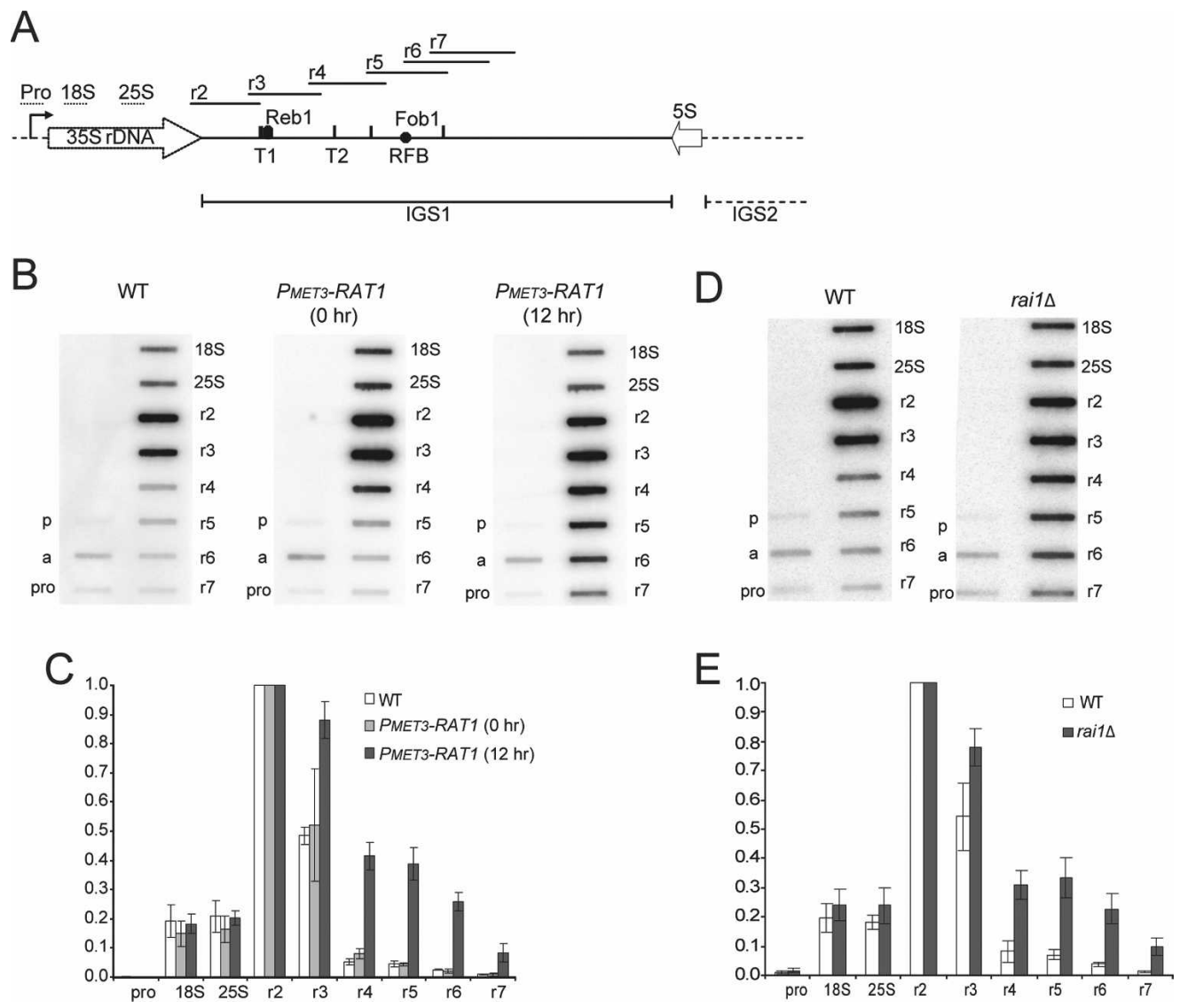

Figure 5. TRO shows read-through of the major Pol I terminator in strains lacking Rat1 or Rail. (A) rDNA schematic showing the positions of M13 phage TRO probes depicted as horizontal bars above the rDNA sequence (see also Prescott et al. 2004). Labels are as in Figure 2A. $(B, C)$ TRO analysis of wild-type and $P_{\text {MET3 }}-R A T 1$ strains. $(B)$ Representative TRO profiles are shown for the isogenic wild type grown in the presence of methionine $(5 \mathrm{mM})$ and for $P_{M E T 3}-R A T 1$ cells grown in the absence $(0 \mathrm{~h})$ or presence of methionine for $12 \mathrm{~h}$ to allow depletion of Rat1. (pro) Promoter; (a) ACT1-positive control. (p) negative control. (C) Quantifications of TRO signals were corrected for background hybridization (probe p) and uracil content, and normalized to probe r2, which was arbitrarily set to 1 . The mean of three independent experiments is shown with standard deviation. Lower signals over the regions encoding the $18 \mathrm{~S}$ and $25 \mathrm{~S}$ rRNAs were observed previously (see the Supplemental Material in Jones et al. 2007) and may reflect quenching of the signals by the highly abundant rRNAs. (D-E) TRO analysis of wild-type and rai1s strains (BY4741 background) grown in minimal medium at $30^{\circ} \mathrm{C}$. $D$ as $B$. $E$ as $C$. Similar data (not shown) were observed with W303-1a background. 
tibodies directed against Rpa190 (data not shown). Similar results were obtained for the two Pol I subunits.

In wild-type cells (data not shown) or in $P_{M E T 3}-R A T 1$ cells grown under permissive conditions $(0-\mathrm{h}$ sample in Fig. 6B) a peak of Pol I association with the rDNA was seen with the igs 1.3 primers, around the position of the T1 terminator (see Fig. 6A for locations of primers). This association decreased over the igs 1.2 primers located over T2 and the RFB and reached background levels over the igs 1.1 primers located further downstream in IGS1. Note that the close proximity of $\mathrm{T} 2$ and the RFB prevents clear discrimination between Pol I associated with these sites by ChIP. Following depletion of Rat1 (12-h sample in Fig. 6B) the peak of Pol I association was displaced from the igs1.3 primers (T1) to igs1.2 (T2/RFB region), consistent with transcription read-through of $\mathrm{T} 1$. The peaks of Pol I association were observed in the same positions using the $P_{M E T 3}-R A T 1$, xrn1s strain (Fig. 6C), although the intensity of the peaks at $12 \mathrm{~h}$ of depletion showed a large variation between different experiments. We conclude that the presence or absence of Xrn1 does not clearly affect Pol I transcription termination.

A

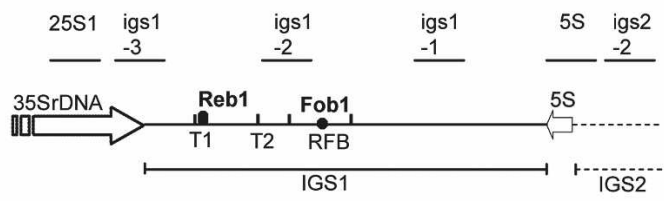

B
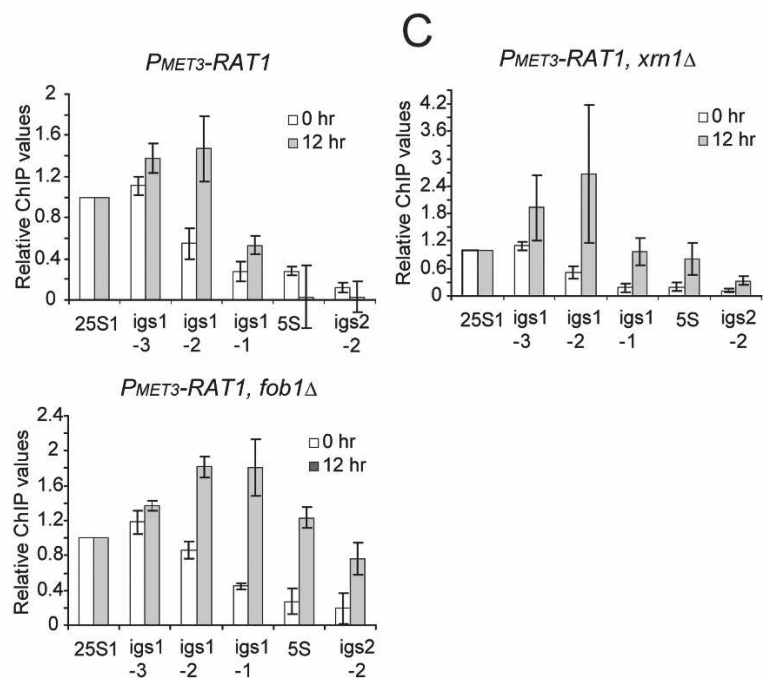

Figure 6. Pol I occupancy over the IGS1 region is increased by depletion of Rat1. (A) rDNA schematic. Horizontal bars above the rDNA denote the locations of products amplified by realtime PCR (see also Supplemental Table S3). Labels are as in Figure 2A. $(B-D)$ Profiles of Pol I cross-linking over the intergenic region of rDNA repeats. Aliquots from strains $P_{M E T 3^{-}} R A T 1(B) ; P_{M E T 3^{-}}$ $R A T 1, x r n 1 \Delta(C)$; and $P_{M E T 3}-R A T 1, f o b 1 \Delta(D)$ were taken at 0 and $12 \mathrm{~h}$ of Rat 1 depletion and processed for Pol I ChIP (Rpa34$13 \mathrm{MYC})$. QPCR values were corrected for background as described in the Materials and Methods and normalized to 25S1, which was set arbitrarily to 1 , in order to compensate for differences in immunoprecipitation efficiencies. The mean of three independent experiments is shown with standard error.
To assess the ability of the RFB to act as a transcription terminator, ChIP analyses were performed on a $P_{\text {MET3 }}$ RAT1, fob1s strain (Fig. 6D). Under permissive conditions for Rat1 expression, the absence of Fob1 did not affect Pol I occupancy across the IGS regions, consistent with TRO data (data not shown). However, following Rat1 depletion, the fob1s strain showed increased Pol I occupancy $3^{\prime}$ to the RFB (igs1.1, 5S and igs 2.2 primers).

Together, these data demonstrate that Rat 1 is required for normal transcription termination by RNA Pol I. Xrn1 does not contribute substantially to termination, but the RFB acts as a terminator when Rat1 is absent and Fob1 is present.

\section{The catalytic activity of Rat1 is required for Pol I termination}

A Rat1 mutant that lacks catalytic activity cannot complement Pol II termination defects on mRNA-coding genes in rat1-1 strains at nonpermissive temperatures (Kim et al. 2004). To determine whether this is also the case for Pol I, the catalytically inactive mutant Rat $1_{\mathrm{D} 235 \mathrm{~A}}$ (Kim et al. 2004) was expressed from a plasmid (kindly provided by Steven Buratowski, Harvard University) in the $P_{\text {MET3 }}-R A T 1$ strain. As controls, the empty vector and a plasmid expressing wild-type Rat1 were also used. As expected, expression of the wild-type Rat1 allowed growth of the $P_{\text {MET3 }}$-RAT1 strain in the presence of $5 \mathrm{mM}$ methionine, whereas no growth was seen in strains carrying the empty vector or expressing Rat $1_{\mathrm{D} 235 \mathrm{~A}}$ (Fig. 7A). This shows that the catalytic activity is required for the essential function of Rat1. The plasmid-expressed proteins carry a tripleHA tag (Kim et al. 2004), and Western blotting showed that the wild-type Rat1 and Rat $1_{\mathrm{D} 235 \mathrm{~A}}$ have similar expression levels (Fig. 7B). Northern analysis for the 5.8S rRNA confirmed that wild-type Rat1, but not Rat $1_{\mathrm{D} 235 \mathrm{~A}}$, complemented the phenotype of Rat1 depletion for $5.8 \mathrm{~S}_{\mathrm{S}}$ and $5.8 \mathrm{~S}_{\mathrm{L}}$ synthesis (Fig. 7C).

The ability of Rat $1_{\mathrm{D} 235 \mathrm{~A}}$ to support Pol I termination was tested by TRO (Fig. 7D-F) and Pol I ChIP (Fig. 7G-I). In TRO analyses, Rat1 depletion for $12 \mathrm{~h}$ strongly enhanced read-through over probes r3-r7 (Fig. 7D). This increase was suppressed by plasmid expression of wildtype Rat1 (Fig. 7E) but not by expression of Rat $1_{\mathrm{D} 235 \mathrm{~A}}$ (Fig. 7F). In ChIP analyses, depletion of Rat1 displaced the Pol I peak from primers igs1.3 (T1) to igs1.2 (T2/RFB) (Fig. 7G). This displacement was suppressed by plasmid expression of wild-type Rat1 (Fig. 7H) but not by expression of Rat $1_{\mathrm{D} 235 \mathrm{~A}}$ (Fig. 7I).

These data show that catalytically inactive Rat1 does not function in 5.8Ss rRNA maturation or in Pol I termination at $\mathrm{T} 1$. This resembles the phenotypes of strains lacking Rail, which show reduced Rat1 activity (Fig. 5; Supplemental Fig. 1). These data strongly support the proposed function of Rat1 as a "torpedo" for Pol I.

\section{Discussion}

In this study, we demonstrate that the $5^{\prime}$-to- $3^{\prime}$ exonuclease Rat 1 plays a role in Pol I transcription termination in 
A

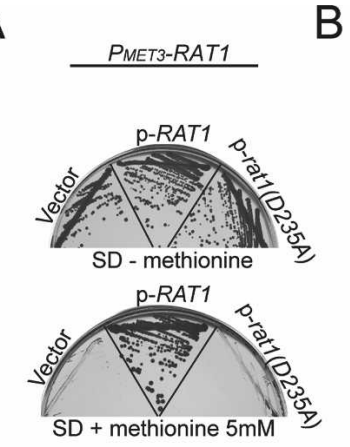

B

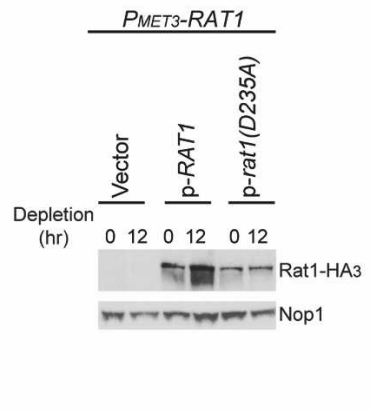

$E$
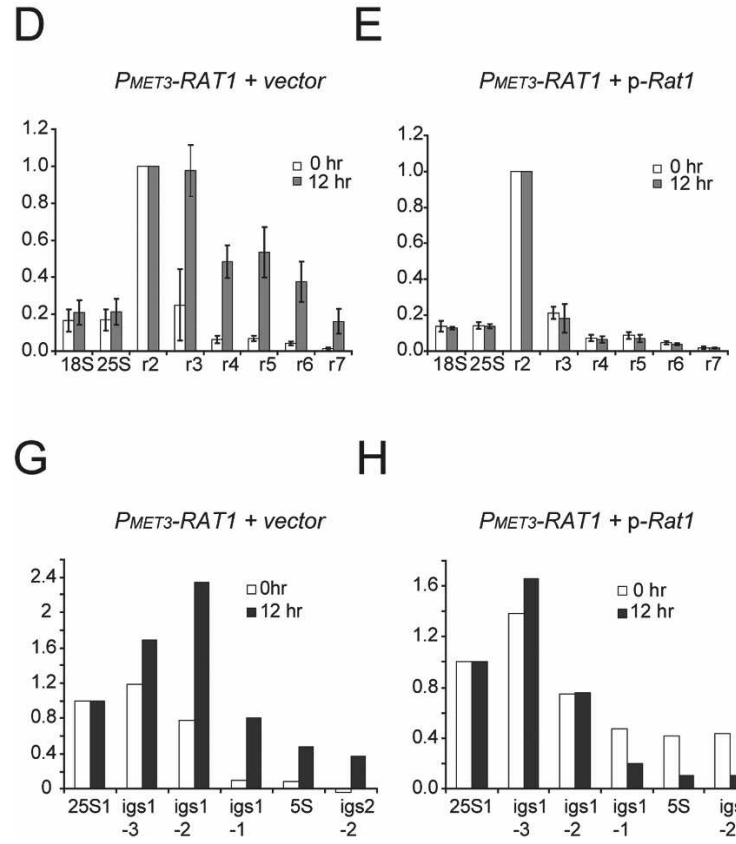

$\mathrm{H}$

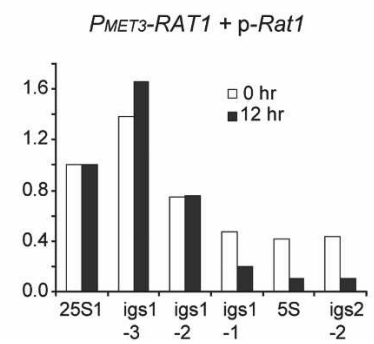

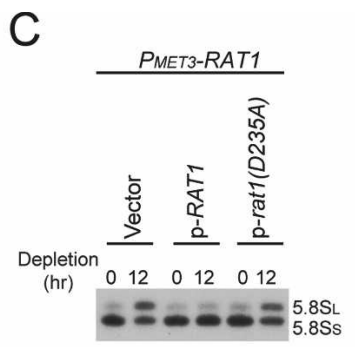

F

PMET3-RAT1 + p-rat1(D235A)

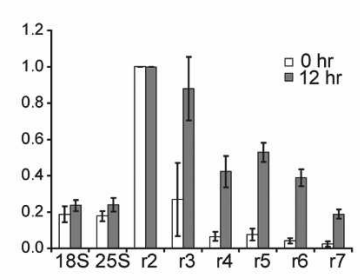

I

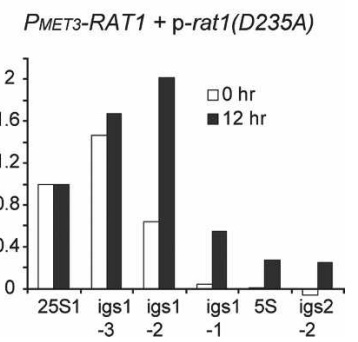

Figure 7. The catalytically inactive mutant Rat $1_{\mathrm{D} 235 \mathrm{~A}}$ does not correct defects in 5.8S rRNA maturation and Pol I termination when Rat1 is depleted. $(A) P_{M E T 3}-R A T 1$ strains transformed with plasmid without insert (vector), with RAT1 (wild type [WT]), or with rat1 (D235A) were tested for growth at $30^{\circ} \mathrm{C}$ on SD-methionine or $\mathrm{SD}+5 \mathrm{mM}$ methionine. $(B)$ Western blot for detection of tagged Rat1 or Rat $1_{\mathrm{D} 235 \mathrm{~A}}$ with $\mathrm{HA}_{3}$. Nop1 detection was used as a loading control. (C) Northern analysis of 5.8S rRNA maturation. RNAs were extracted as described in Figure 1B. Total RNA was resolved on an $8 \%$ polyacrylamide/urea gel. Mature $5.8 \mathrm{~S}_{\mathrm{S}}$ and $5.8 \mathrm{~S}_{\mathrm{L}}$ rRNAs were detected with probe 017 (see Fig. 1A; Supplemental Table S2). $(D-F)$ TRO analysis over the rDNA repeats in strains $P_{\text {MET3 }}-R A T 1+$ vector $(D), P_{M E T 3^{-}}$ $R A T 1+\mathrm{p}-R A T 1(E)$, and $P_{M E T 3}-R A T 1+\mathrm{p}-$ rat1 (D235A) $(F)$. Primers and quantifications are as in Figure 5. The mean of three independent experiments is shown with standard deviation. $(G-I)$ Profiles of Pol I cross-linking over the intergenic region of rDNA repeats in strains $P_{M E T 3^{-}}$ $R A T 1+$ vector $(G), P_{M E T 3}-R A T 1+\mathrm{p}-R A T 1$ $(H)$, and $P_{M E T 3}-R A T 1+$ p-rat1 $(D 235 A)(I)$. Primers and quantifications are as described in Figure 6. A representative graph of two independent experiments is shown.
S. cerevisiae. The model illustrated in Figure 8 resembles the torpedo model described for mRNA transcription termination (Kim et al. 2004; West et al. 2004). The 35S pre-rRNA is cleaved cotranscriptionally by Rnt 1 across a stem-loop structure, at positions $+14 / 15$ and $+49 / 50,3^{\prime}$ to the 25S rRNA. These cleavages form the entry sites for Rat1, which attacks the nascent RNA downstream from the cleavage sites. Rat 1 potentially catches up with the polymerase, which is predicted to be paused at the major, "Reb1-dependent" T1 terminator (Reeder and Lang 1997). Cotranscriptional degradation by Rat1 might trigger the release of Pol I from the DNA template through the destabilization of the 8- to 9-nt RNA/DNA hybrid and/or the disruption of RNA-protein interactions implicated in the stabilization of Pol I complexes. Previous analyses suggested the existence of a transcript release factor for Pol I termination in yeast (Reeder and Lang 1997; Tschochne and Milkereit 1997; Jansa and Grummt 1999), which might correspond to Rat1.

The Rat1-interacting protein Rail is required for efficient 5 ' maturation of 5.8S rRNA and termination of Pol II transcription (Xue et al. 2000; Kim et al. 2004), and was also required for efficient Pol I termination. Rail was, however, dispensable for pre-rRNA transcript degradation following Rnt1 cleavage. Conversely, Xrn1 was able to degrade the cleaved IGS1 transcripts in the absence of Rat1, but did not participate in transcription termination. $\mathrm{Xrn} 1$ is reported to be cytoplasmic exclusively (Johnson 1997), and it may therefore be unable to interact with nuclear termination factors and/or fail to degrade the prerRNA cotranscriptionally. We speculate that increased Pol I read-through in the rails strain may reflect slowed loading or reduced processivity of Rat1 in the absence of its cofactor, preventing it from catching the polymerase within this short time window. This model was strengthened by the observation that catalytically inactive Rat $1_{\mathrm{D} 235 \mathrm{~A}}$ fails to complement Pol I termination defects seen on depletion of wild-type Rat1. These features resemble pre-rRNA processing, where loss of either Rat1 or Rail impairs processing of the 5 '-extended precursor to $5.8 \mathrm{~S}$ rRNA. This leads to a decrease in $5.8 \mathrm{~S}_{\mathrm{S}}$ rRNA relative to the alternative $5.8 \mathrm{~S}_{\mathrm{L}}$ species, consistent with a short time window for productive processing to $5.8 \mathrm{~S}_{\mathrm{S}}$. In contrast, Xrn1 degrades 5'-extended 5.8S rRNA species that would otherwise accumulate in the absence of Rat1 activity, but does not contribute to $5.8 \mathrm{~S}_{\mathrm{S}}$ maturation. 

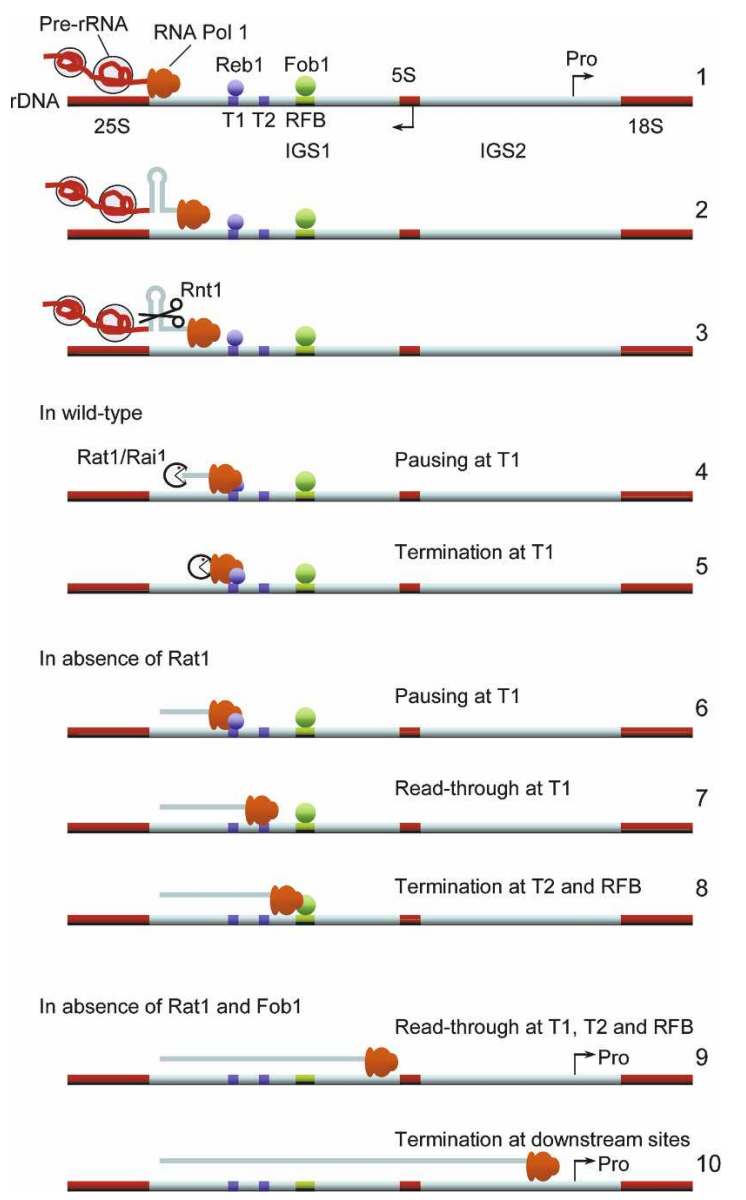

Figure 8. Model for the role of Rat 1 as a torpedo in Pol I transcription termination. (1) The elongating Pol I carries the nascent pre-rRNA, which assembles cotranscriptionally with ribosome synthesis factors. (2) Pol I transcribes through Rnt1 cleavage sites in IGS1. (3) The pre-rRNA is cleaved cotranscriptionally across a stem-loop structure by Rnt $1 .(4,5)$ In wild-type cells, these cleavages form the entry site for the Rat1/Rail complex. This complex degrades the nascent transcript and catches the polymerase, which is predicted to be paused at site $\mathrm{T} 1$, stimulating transcription termination. (6-8) In the absence of Rat1, the polymerase largely transcribes through $\mathrm{T} 1$ but terminates at T2 and the RFB. $(9,10)$ In the absence of both Rat 1 and Fob1, RNA polymerases can transcribe through T2 and the RFB and terminate upstream of the $5 \mathrm{~S}$ gene or in IGS2.

In ChIP analyses, levels of Rat 1 over the rDNA 3'-ETS region were lower than over the $3^{\prime}$ regions of the Pol II genes $A D H 1$ and $C Y C 1$. In the case of Pol II termination, Ratl interacts with CTD-binding protein Rtt103 and other 3 '-end processing factors (Kim et al. 2004; Luo et al. 2006). This might strengthen the cross-linking of Ratl to the Pol II transcribed DNA. In contrast, Rat1 has not been reported to interact directly with RNA Pol I, so positive ChIP signals on the rDNA require cross-linking of Ratl to the nascent transcript, bound to the transcribing polymerase, bound to the DNA. The relatively low Rat1 ChIP signal over the rDNA IGS1 region is also likely to reflect its very short residency times, consistent with the very rapid and efficient rRNA processing path- way. Pol I requires only 1-2 sec to transcribe the $44 \mathrm{nt}$ from the major Rnt 1 cleavage site $(+50$ relative to $25 \mathrm{~S}$ sequence) to T1 (+93). The "Reb1-dependent" terminator may pause Pol I (Reeder et al. 1999; Prescott et al. 2004), allowing more time for termination to occur, but the high rate of rDNA transcription (around one transcript is completed every $3 \mathrm{sec}$ on each active rDNA repeat) suggests that the time available will still be very limited. Note also that ChIP signals derived from rDNA transcription units will be diluted by the nontranscribed rDNA repeats, which account for half of the rDNA array.

Our ChIP data localized Rat1 to both IGS1 and the 5' region of the $35 \mathrm{~S}$ rDNA, possibly reflecting looping of the rDNA as proposed previously (Johnson and Warner 1989; Kulkens et al. 1992). This might arise through oligomerization of Reb1, since this binds the rDNA at T1 in IGS1 and just upstream of the Pol I promoter in IGS2 (Reeder and Lang 1997). Such loops have been detected recently between the $5^{\prime}$ and $3^{\prime}$ ends of proteincoding genes (O'Sullivan et al. 2004; Ansari and Hampsey 2005). However, Rat 1 also functions in the $5^{\prime}$ maturation of the $5.8 \mathrm{~S}$ and $25 \mathrm{~S}$ rRNAs, and in the rapid degradation of other excised pre-rRNA spacer fragments (Henry et al. 1994; Petfalski et al. 1998; Geerlings et al. 2000). It is therefore also possible that Ratl is loaded cotranscriptionally onto the nascent pre-rRNA to promote efficient pre-rRNA processing, as has been reported for other ribosome synthesis factors (Gallagher et al. 2004). Moreover, processing in ITS1, where Rat1 functions in 5.8S synthesis, and processing in IGS1 are reported to be coupled (Allmang and Tollervey 1998), suggesting further interactions.

In addition to the Rat1/Rail complex, other factors presumably play roles in Pol I termination. The small Pol I subunit Rpa12 can interact directly with Rnt1 (Catala et al. 2008) and the absence of Rpa12 or Rnt1 leads to Pol I read-through over IGS1 (Reeder et al. 1999; Prescott et al. 2004; Catala et al. 2008). The absence of Rpa12 might interfere directly with cotranscriptional cleavage by Rnt1, preventing loading of the Rat1/Rail complex. However, nascent IGS1 transcripts were not observed in rpa12s strains in Miller spreads (Prescott et al. 2004), suggesting that degradation of the transcripts is ongoing. Other possible models for read-through in rpa12s strains include a failure of the defective Pol I to pause at termination sites or alterations in Pol I conformation that render it more refractory to the torpedo activity of Rat1/Rail. Notably, efficient termination of mRNA synthesis requires both a change in Pol II conformation downstream from the cleavage/polyadenylation site and the degradation of the $3^{\prime}$ transcript by Rat1/Rail (Luo et al. 2006; Rosonina et al. 2006).

In the absence of Rat1, Pol I reads through the major $\mathrm{T} 1$ terminator but stops at $\mathrm{T} 2$ and the RFB. The absence of the RFB-binding protein Fob1 alone had no effect on termination at $\mathrm{Tl}$, but in the absence of both Rat 1 and Fob1 a substantial fraction of Pol I transcribed the entire IGS1 region. Thus, in addition to its key roles in rDNA metabolism, the RFB serves as an extra barrier for Pol I transcription. T2 and the "Fob1-dependent" terminator 
might cooperate to ensure that any Pol I complexes that escape $\mathrm{T} 1$ do not collide with rDNA replication forks moving toward the RFB in opposite orientation to Pol I during S phase (Takeuchi et al. 2003).

The loss of Fob1 from the Rat1-depleted strain also reduced but did not abolish termination at $\mathrm{T} 2$. The sequence of T2, which is extremely dT-rich, probably leads to slippage of Pol I, with reiterative synthesis leading to formation of long poly $(\mathrm{U})$ tracts as seen previously in vitro (Jeong et al. 1996). It is therefore possible that T2 possesses some intrinsic termination activity. Elongation of Pol I through T2 (and elsewhere downstream in IGS1 and IGS2) might also be impaired by formation of R-loops, generated by interactions between the IGS1 transcripts, which may not be packaged by the ribosome synthesis machinery, and the rDNA (Tous and Aguilera 2007).

Other factors that potentially contribute to termination at T2 include the Nrd1-Nab3 complex (M. Koper and J. Kufel, unpubl.) or the TRAMP and exosome complexes. These function in the termination and degradation of noncoding RNAs that are transcribed through the $\mathrm{RFB} / \mathrm{T} 2$ region by Pol II in the opposite orientation to Pol I (Houseley et al. 2007; Vasiljeva et al. 2008). The noncoding RNAs are generated at levels very much lower than the pre-rRNA, but might also influence Pol I termination at $\mathrm{T} 2$ and the RFB via effects on chromatin structure.

In mammals, the Pol I terminator is an 18-base-pair (bp) sequence motif called the Sal box that is repeated 10 times (sites T1-T10) downstream from the $3^{\prime}$ end of the pre-RNA coding region. The first eight Sal boxes are recognized by TTF-1, which mediates both RNA Pol I termination (Kuhn and Grummt 1989) and rDNA replication fork stalling (Gerber et al. 1997). However, TTF-1 blocks rDNA replication only when bound to Sal box T2 (Gerber et al. 1997), which lies $122 \mathrm{nt}$ away from the major site of transcription arrest at Sal box T1, physically separating these processes. Yeast Reb1 is homologous with TTF-1, since the C-terminal halves of both proteins share homology with the DNA-binding domain of the proto-oncoprotein c-Myb (for review, see Reeder and Lang 1997), whereas Fob1 is functionally related to TTF-1 in blocking replication fork progression. Thus, in both systems the major site of Pol I termination and the RFB are physically separated, although there are mechanistic differences. No RNase III cleavage site has yet been identified at the $3^{\prime}$ end of the mammalian $28 \mathrm{~S}$ rRNA, but a $3^{\prime}$ exonuclease trims the pre-28S after release of RNA Pol I (Kuhn and Grummt 1989). The release factor implicated in Pol I termination in mammals is PTRF, which is unrelated to Rat1 (Jansa and Grummt 1999). The involvement of mammalian Xrn2 in Pol I termination has not been addressed, but these observations suggest that it may not have the same role as yeast Rat1.

The model proposed here for transcription termination by Pol I shows striking similarities to current models for Pol II termination on protein-coding genes. These, too, invoke cotranscriptional cleavage, providing an entry site for Rat1/Rail or Xrn2 (Kim et al. 2004; West et al. 2004; Kaneko et al. 2007), which then catch the polymerase at downstream pause sites (Gromak et al. 2006). The results reveal potentially important links between the transcriptional and post-transcriptional steps in rRNA synthesis, and between ribosome biogenesis and mRNA synthesis.

\section{Materials and methods}

Strains, plasmids, and growth conditions

Yeast strains and plasmids used in this study are listed in

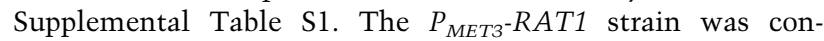
structed by one-step PCR strategy using plasmid pTLN28ff (van Nues and Beggs 2001). xrn1s, rai1s, or fob1s deletions (template plasmids pFA6a-kanMX6/NatMX6) and the C-terminal $13 \mathrm{Myc}$ construct (template plasmid pFA6a-13MYC::Hph; a generous gift from R. Grainger) were performed as described (Longtine et al. 1998).

Growth and handling of $S$. cerevisiae were by standard techniques. For Rat1 depletion, cells $\left(P_{\text {MET3 }}-R A T 1\right.$ strains $)$ were grown at $30^{\circ} \mathrm{C}$ to $\mathrm{OD}_{600} \sim 0.3-0.4$ in $\mathrm{SD}$ medium lacking methionine, then were transferred to the same prewarmed medium supplemented with methionine $(5 \mathrm{mM})$. The growth was continued for several hours and maintained in exponential phase by dilution with prewarmed SD medium with methionine.

\section{RNA analyses}

RNA extractions, Northern hybridization, and primer extension were as described (Thomson and Tollervey 2005). Standard $1.2 \%$ agarose/glyoxal gel or $6 \%$ or $8 \%$ acrylamide/8.3 M urea gels were used to separate high- or low-molecular-weight RNAs. Primers for RNA analysis are listed in Supplemental Table S2. To detect RAT1 mRNA (3.02 kb), a random priming probe was prepared according to Strip-EZTM (Ambion) using primers RatlmRNA-F and RatlmRNA-R (Supplemental Table S2). Northern hybridization was done overnight at $42^{\circ} \mathrm{C}$ using ULTRAHyb buffer (Ambion), and stringent washes were done at $58^{\circ} \mathrm{C}$ with SSC $0.2 \times$ SDS $0.1 \%$.

\section{Western blots}

Total protein extracts and Western blot analysis were performed using standard procedures. Noplp was detected with a mouse anti-Nop1 antibody (kindly provided by J. Aris, University of Florida). Rat1- $\mathrm{HA}_{3}$ tag was detected with mouse anti-HA sc7392 antibody (Santa Cruz Biotechnology).

\section{ChIP}

Yeast cells $\left(75 \mathrm{~mL}\right.$ of $0.5-0.7 \mathrm{~A}_{600} / \mathrm{mL} ; 12.5 \mathrm{~mL}$ per immunoprecipitation) were cross-linked with formaldehyde ( $1 \%$ final) for $15 \mathrm{~min}$ (TAP-tagged proteins) or $30 \mathrm{~min}$ (Pol I), quenched with glycine (137.5 mM) for $10 \mathrm{~min}$, and washed with ice-cold PBS $1 \times$. Cells were resuspended with $350 \mu \mathrm{L}$ of lysis buffer (50 $\mathrm{mM}$ HEPES-KOH at $\mathrm{pH} 7.5,140 \mathrm{mM} \mathrm{NaCl}, 1 \mathrm{mM}$ EDTA at $\mathrm{pH}$ $8,1 \%$ Triton $\mathrm{X}-100,0.1 \% \mathrm{w} / \mathrm{v}$ sodium deoxycholate, plus CPI $1 \times$ [Roche Protease inhibitor cocktail tablets containing EDTA]), mixed with $500 \mu \mathrm{L}$ of glass beads (Sigma, G8772), and vortexed (Vortex Genie 2T, Scientific Industries) for $45 \mathrm{~min}$ at full speed at $4{ }^{\circ} \mathrm{C}$. Glass beads were removed and cross-linked chromatin was recovered by centrifugation at full speed for 10 min at $4^{\circ} \mathrm{C}$ (supernatant discarded). Six-hundred microliters of 
lysis buffer were added on the top of the pellet. Sonication of chromatin was performed for $1 \mathrm{~min} 30 \mathrm{sec}$ (10 sec ON, $15 \mathrm{sec}$ OFF, 20\% amplitude; Branson Digital Sonifier) to yield an average DNA fragment size of $\sim 500$ bp. "Cells" were spun for 30 min at full speed at $4^{\circ} \mathrm{C}$. The supernatant $(\sim 600 \mu \mathrm{L})$ was diluted 1:1 with lysis buffer supplemented with glycerol $10 \%$. Twohundred microliters of lysate were mixed with $20 \mu \mathrm{L}$ (bed volume) of protein A sepharose Cl-4B beads (GE Healthcare) (for rabbit antibody) or Gammabind G sepharose beads (GE Healthcare) (for mouse antibody) and cleared for $1 \mathrm{~h}$ at $4^{\circ} \mathrm{C}$. Ten microliters were kept for Input DNA. Immunoprecipitations were performed by adding $12.5 \mu \mathrm{L}$ of anti-Myc mAb9E10 (Santa Cruz Biotechnology) for Rpa34-13MYC ChIPs, or $4 \mu \mathrm{L}$ of anti-Rpa190 (generous gift from Michel Riva, CEA-Saclay-France; or our affinity-purified rabbit antibody from Eurogentec) for Rpa190 ChIPs. To assess contribution of background, a "beads-only" internal control was usually prepared in parallel to immunoprecipitated samples but without addition of any antibody. Beads, antibody, and "cleared-sonicated chromatin" were mixed on a rotating wheel overnight at $4^{\circ} \mathrm{C}$. Beads were recovered and washed successively with lysis buffer, lysis buffer with $500 \mathrm{mM}$ $\mathrm{NaCl}$, wash buffer $(10 \mathrm{mM}$ Tris- $\mathrm{HCl}$ at $\mathrm{pH} 8,0.25 \mathrm{M} \mathrm{LiCl}, 0.5 \%$ NP-40, $0.5 \% \mathrm{w} / \mathrm{v}$ sodium deoxycholate, $1 \mathrm{mM}$ EDTA at $\mathrm{pH} 8$, plus CPI $1 \times)$, and TE (100 $\mathrm{mM}$ Tris- $\mathrm{Cl}$ at $\mathrm{pH} 8,10 \mathrm{mM}$ EDTA at $\mathrm{pH} 8)$ at $4^{\circ} \mathrm{C}$. Cross-link reversal was done by incubating the washed beads overnight at $65^{\circ} \mathrm{C}$ in $125 \mu \mathrm{L}$ of TE buffer containing $1 \%$ SDS. After proteinase $\mathrm{K}$ treatment $(900 \mu \mathrm{g} / \mathrm{mL})$ for $3 \mathrm{~h}$ at $55^{\circ} \mathrm{C}$, DNA was purified using Qiagen PCR purification kit and eluted with $70 \mu \mathrm{L}$ of buffer EB containing RNase A $(0.5 \mu \mathrm{g} / \mathrm{mL})$. In the case of TAP-tagged proteins, immunoprecipitations were performed as above but using sepharose CL-4B beads (Sigma) for the clearing step and IgG sepharose 6 Fast Flow beads (GE Healthcare) for the immunoprecipitations. To assess the background, the nontagged strain was used in parallel as an external control.

Quantitative PCRs (qPCRs) were performed in triplicate with SYBR green JumpStart Taq ReadyMix (Sigma) and a Stratagene MX3005P real-time PCR machine. Reaction volumes were 10 $\mu \mathrm{L}: 5 \mu \mathrm{L}$ of Mix, $0.05 \mu \mathrm{L}$ of Rox, $0.03 \mu \mathrm{L}$ of each primer (300 nM), and $1 \mu \mathrm{L}$ of template. Cycling parameters were $2 \mathrm{~min}$ at $95^{\circ} \mathrm{C}$, then 40 cycles of $10 \mathrm{sec}$ at $95^{\circ} \mathrm{C}, 10 \mathrm{sec}$ at $55^{\circ} \mathrm{C}$, and $15 \mathrm{sec}$ at $72^{\circ} \mathrm{C}$. Primers used for real-time PCR are listed in Supplemental Table S3.

Values for ChIPs were determined using the formula $\Delta \Delta \mathrm{Ct}=2^{-(\Delta \mathrm{Ct} \text { IP }-\Delta \mathrm{Ct} \text { Background })}$. "Ct IP" is the cycle number for immunoprecipitate, and "Ct Background" is the cycle number for external control (isogenic nontagged strain in the case of TAPtagged proteins in Fig. 4) or the cycle number for internal control (without antibody in the case of Pol I in Figs. 6, 7). $\Delta \mathrm{Ct} \quad \mathrm{IP}=\mathrm{Ct} \quad \mathrm{IP}-\mathrm{Ct}$ Input DNA. $\Delta \mathrm{Ct} \quad$ Background $=\mathrm{Ct}$ Background - Ct Input DNA. In the case of Pol I ChIPs (Figs. 6, 7), $\Delta \Delta \mathrm{Ct}$ for ADH1-1 primers (ADH1 is a Pol II transcribed gene) was subtracted from $\Delta \Delta \mathrm{Ct}$ for each rDNA primer set.

\section{TRO analysis}

TRO assay was performed essentially as described (Birse et al. 1997) with the following modifications. Fifty milliliters of cells were harvested, washed, and permeabilized in $0.5 \%$ sarkosyl for $20 \mathrm{~min}$ at $4^{\circ} \mathrm{C}$. Cells were resuspended in transcription buffer with the addition of $2 \mathrm{mM}$ DTT and $1.33 \mathrm{mM}$ each ATP, GTP, and CTP. Transcription was allowed to proceed for $5 \mathrm{~min}$ at $30^{\circ} \mathrm{C}$ in the presence of $30-60 \mu \mathrm{Ci}$ of $\left[\alpha^{32} \mathrm{P}\right] \mathrm{UTP}$ (3000 Ci $\mathrm{mMol}^{-1}$; Hartmann Analytic). Cells were then washed with $\mathrm{AE}$ buffer (NaAc $50 \mathrm{mM}$, EDTA $10 \mathrm{mM}$ ) and RNA was extracted using GTC/phenol and the zirconia-silica beads method. RNA was partially hydrolyzed with $0.2 \mathrm{M} \mathrm{NaOH}$ for $5 \mathrm{~min}$ at $4^{\circ} \mathrm{C}$ and neutralized by addition of $0.4 \mathrm{vol}$ of $0.5 \mathrm{M}$ Tris-HCl. Singlestranded M13 phage constructs were used for hybridization as described (Prescott et al. 2004). Probes (5 $\mu$ g per slot) were immobilized on Bright-Star nylon membrane (Ambion) using BioDot Microfiltration Apparatus (Bio-Rad) and UV-cross-linked. Filters were hybridized overnight at $42^{\circ} \mathrm{C}$ in $5 \times$ SSC, $50 \%$ formamide, $0.05 \%$ SDS, $10 \times$ Denhardt's solution. Autoradiographs were visualized using FujiFilm FLA-7000 scanner and quantified using FujiFilm Multi Gauge version 3.0 software.

\section{Acknowledgments}

We are indebted to Nick Proudfoot for M13 phage constructs, Michel Riva for anti-Rpa190, and Steven Buratowski and Minkyu Kim for pRS315 plasmids. We thank Bernhard Dichtl, Maria Vogelauer, Kim Kotovic, Martin Kos, Emma Thomson, Steve Innocente, Richard Grainger, David Barrass, Olivier Cordin, and Aracelli Castillo for advice and/or critical reading of manuscript. We thank Kawa.Ska Sp. Z o.o. (Zalesie Gorne, Poland) for the FujiFilm FLA-7000 system. A.E.H. was the recipient of an EMBO fellowship. This work was supported by EU grant LSHG-CT-2005-518280 and the Wellcome Trust.

\section{References}

Alen, C., Kent, N.A., Jones, H.S., O'Sullivan, J., Aranda, A., and Proudfoot, N.J. 2002. A role for chromatin remodeling in transcriptional termination by RNA polymerase II. Mol. Cell 10: $1441-1452$.

Allmang, C. and Tollervey, D. 1998. The role of the 3' external transcribed spacer in yeast pre-rRNA processing. J. Mol. Biol. 278: 67-78.

Amberg, D.C., Goldstein, A.L., and Cole, C.N. 1992. Isolation and characterization of RAT1: An essential gene of Saccharomyces cerevisiae required for the efficient nucleocytoplasmic trafficking of mRNA. Genes \& Dev. 6: 1173-1189.

Ansari, A. and Hampsey, M. 2005. A role for the CPF $3{ }^{\prime}$-end processing machinery in RNAP II-dependent gene looping. Genes \& Dev. 19: 2969-2978.

Awrey, D.E., Weilbaecher, R.G., Hemming, S.A., Orlicky, S.M., Kane, C.M., and Edwards, A.M. 1997. Transcription elongation through DNA arrest sites. A multistep process involving both RNA polymerase II subunit RPB9 and TFIIS. J. Biol. Chem. 272: 14747-14754.

Birse, C.E., Lee, B.A., Hansen, K., and Proudfoot, N.J. 1997. Transcriptional termination signals for RNA polymerase II in fission yeast. EMBO J. 16: 3633-3643.

Catala, M., Tremblay, M., Samson, E., Conconi, A., and Abou Elela, S. 2008. Deletion of Rntlp alters the proportion of open versus closed rDNA repeats in yeast. Mol. Cell. Biol. 28: 619-629.

Gallagher, J.E., Dunbar, D.A., Granneman, S., Mitchell, B.M., Osheim, Y., Beyer, A.L., and Baserga, S.J. 2004. RNA polymerase I transcription and pre-rRNA processing are linked by specific SSU processome components. Genes \& Dev. 18: 2506-2517.

Geerlings, T.H., Vos, J.C., and Raue, H.A. 2000. The final step in the formation of 25S rRNA in Saccharomyces cerevisiae is performed by $5^{\prime} \rightarrow 3^{\prime}$ exonucleases. RNA 6: 1698-1703.

Gerber, J.K., Gogel, E., Berger, C., Wallisch, M., Muller, F., Grummt, I., and Grummt, F. 1997. Termination of mammalian rDNA replication: Polar arrest of replication fork movement by transcription termination factor TTF-I. Cell 90: 
$559-567$.

Gromak, N., West, S., and Proudfoot, N.J. 2006. Pause sites promote transcriptional termination of mammalian RNA polymerase II. Mol. Cell. Biol. 26: 3986-3996.

Henras, A.K., Bertrand, E., and Chanfreau, G. 2004. A cotranscriptional model for 3 '-end processing of the Saccharomyces cerevisiae pre-ribosomal RNA precursor. RNA 10: 1572-1585.

Henry, Y., Wood, H., Morrissey, J.P., Petfalski, E., Kearsey, S., and Tollervey, D. 1994. The $5^{\prime}$ end of yeast 5.8S rRNA is generated by exonucleases from an upstream cleavage site. EMBO J. 13: 2452-2463.

Houseley, J., Kotovic, K., El Hage, A., and Tollervey, D. 2007. Trf4 targets ncRNAs from telomeric and rDNA spacer regions and functions in rDNA copy number control. EMBO $J$. 26: 4996-5006.

Huang, J., Brito, I.L., Villen, J., Gygi, S.P., Amon, A., and Moazed, D. 2006. Inhibition of homologous recombination by a cohesin-associated clamp complex recruited to the rDNA recombination enhancer. Genes \& Dev. 20: 2887-2901.

Jansa, P. and Grummt, I. 1999. Mechanism of transcription termination: PTRF interacts with the largest subunit of RNA polymerase I and dissociates paused transcription complexes from yeast and mouse. Mol. Gen. Genet. 262: 508-514.

Jeong, S.W., Lang, W.H., and Reeder, R.H. 1996. The yeast transcription terminator for RNA polymerase I is designed to prevent polymerase slippage. J. Biol. Chem. 271: 16104-16110.

Johnson, A.W. 1997. Ratlp and Xrnlp are functionally interchangeable exoribonucleases that are restricted to and required in the nucleus and cytoplasm, respectively. Mol. Cell. Biol. 17: 6122-6130.

Johnson, S.P. and Warner, J.R. 1989. Unusual enhancer function in yeast rRNA transcription. Mol. Cell. Biol. 9: 4986-4993.

Jones, H.S., Kawauchi, J., Braglia, P., Alen, C.M., Kent, N.A., and Proudfoot, N.J. 2007. RNA polymerase I in yeast transcribes dynamic nucleosomal rDNA. Nat. Struct. Mol. Biol. 14: $123-130$.

Kaneko, S., Rozenblatt-Rosen, O., Meyerson, M., and Manley, J.L. 2007. The multifunctional protein $\mathrm{p} 54 \mathrm{nrb} / \mathrm{PSF}$ recruits the exonuclease XRN2 to facilitate pre-mRNA 3' processing and transcription termination. Genes \& Dev. 21: 1779-1789.

Kim, M., Krogan, N.J., Vasiljeva, L., Rando, O.J., Nedea, E., Greenblatt, J.F., and Buratowski, S. 2004. The yeast Rat1 exonuclease promotes transcription termination by RNA polymerase II. Nature 432: 517-522.

Kufel, J., Dichtl, B., and Tollervey, D. 1999. Yeast Rntlp is required for cleavage of the pre-ribosomal RNA in the 3' ETS but not the 5' ETS. RNA 5: 909-917.

Kuhn, A. and Grummt, I. 1989. 3'-end formation of mouse prerRNA involves both transcription termination and a specific processing reaction. Genes \& Dev. 3: 224-231.

Kulkens, T., van der Sande, C.A., Dekker, A.F., van Heerikhuizen, H., and Planta, R.J. 1992. A system to study transcription by yeast RNA polymerase I within the chromosomal context: Functional analysis of the ribosomal DNA enhancer and the RBP1/REB1 binding sites. EMBO J. 11: 46654674.

Lang, W.H. and Reeder, R.H. 1993. The REB1 site is an essential component of a terminator for RNA polymerase I in Saccharomyces cerevisiae. Mol. Cell. Biol. 13: 649-658.

Longtine, M.S., McKenzie III, A., Demarini, D.J., Shah, N.G., Wach, A., Brachat, A., Philippsen, P., and Pringle, J.R. 1998. Additional modules for versatile and economical PCR-based gene deletion and modification in Saccharomyces cerevisiae. Yeast 14: 953-961.

Luo, W., Johnson, A.W., and Bentley, D.L. 2006. The role of Rat1 in coupling mRNA $3{ }^{\prime}$-end processing to transcription termi- nation: Implications for a unified allosteric-torpedo model. Genes \& Dev. 20: 954-965.

Lygerou, Z., Allmang, C., Tollervey, D., and Seraphin, B. 1996. Accurate processing of a eukaryotic precursor ribosomal RNA by ribonuclease MRP in vitro. Science 272: 268-270.

O'Sullivan, J.M., Tan-Wong, S.M., Morillon, A., Lee, B., Coles, J., Mellor, J., and Proudfoot, N.J. 2004. Gene loops juxtapose promoters and terminators in yeast. Nat. Genet. 36: 10141018.

Petfalski, E., Dandekar, T., Henry, Y., and Tollervey, D. 1998. Processing of the precursors to small nucleolar RNAs and rRNAs requires common components. Mol. Cell Biol. 18: 1181-1189.

Prescott, E.M., Osheim, Y.N., Jones, H.S., Alen, C.M., Roan, J.G., Reeder, R.H., Beyer, A.L., and Proudfoot, N.J. 2004. Transcriptional termination by RNA polymerase I requires the small subunit Rpa12p. Proc. Natl. Acad. Sci. 101: 6068-6073.

Reeder, R.H. and Lang, W. 1994. The mechanism of transcription termination by RNA polymerase I. Mol. Microbiol. 12: $11-15$.

Reeder, R.H. and Lang, W.H. 1997. Terminating transcription in eukaryotes: Lessons learned from RNA polymerase I. Trends Biochem. Sci. 22: 473-477.

Reeder, R.H., Guevara, P., and Roan, J.G. 1999. Saccharomyces cerevisiae RNA polymerase I terminates transcription at the Reb1 terminator in vivo. Mol. Cell. Biol. 19: 7369-7376.

Rosonina, E., Kaneko, S., and Manley, J.L. 2006. Terminating the transcript: Breaking up is hard to do. Genes \& Dev. 20: $1050-1056$.

Stevens, A. and Poole, T.L. 1995. 5'-exonuclease-2 of Saccharomyces cerevisiae. Purification and features of ribonuclease activity with comparison to $5^{\prime}$-exonuclease-1. J. Biol. Chem. 270: 16063-16069.

Takeuchi, Y., Horiuchi, T., and Kobayashi, T. 2003. Transcription-dependent recombination and the role of fork collision in yeast rDNA. Genes \& Dev. 17: 1497-1506.

Thomson, E. and Tollervey, D. 2005. Nop53p is required for late $60 \mathrm{~S}$ ribosome subunit maturation and nuclear export in yeast. RNA 11: 1215-1224.

Tous, C. and Aguilera, A. 2007. Impairment of transcription elongation by R-loops in vitro. Biochem. Biophys. Res. Commun. 360: 428-432.

Tschochne, H. and Milkereit, P. 1997. RNA polymerase I from $S$. cerevisiae depends on an additional factor to release terminated transcripts from the template. FEBS Lett. 410: 461-466.

van der Sande, C.A., Kulkens, T., Kramer, A.B., de Wijs, I.J., van Heerikhuizen, H., Klootwijk, J., and Planta, R.J. 1989. Termination of transcription by yeast RNA polymerase I. Nucleic Acids Res. 17: 9127-9146.

van Nues, R.W. and Beggs, J.D. 2001. Functional contacts with a range of splicing proteins suggest a central role for Brr2p in the dynamic control of the order of events in spliceosomes of Saccharomyces cerevisiae. Genetics 157: 1451-1467.

Vasiljeva, L., Kim, M., Terzi, N., Soares, L.M., and Buratowski, S. 2008. Transcription termination and RNA degradation contribute to silencing of RNA polymerase II transcription within heterochromatin. Mol. Cell 29: 313-323.

West, S., Gromak, N., and Proudfoot, N.J. 2004. Human $5^{\prime} \rightarrow 3^{\prime}$ exonuclease Xrn2 promotes transcription termination at cotranscriptional cleavage sites. Nature 432: 522-525.

Xue, Y., Bai, X., Lee, I., Kallstrom, G., Ho, J., Brown, J., Stevens, A., and Johnson, A.W. 2000. Saccharomyces cerevisiae RAI1 (YGL246c) is homologous to human DOM3Z and encodes a protein that binds the nuclear exoribonuclease Ratlp. Mol. Cell. Biol. 20: 4006-4015. 


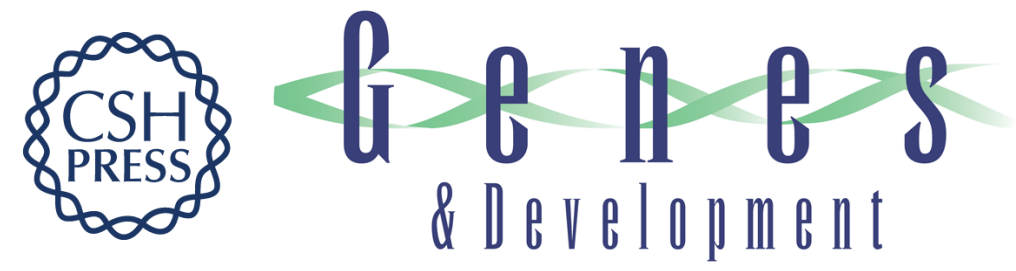

\section{Efficient termination of transcription by RNA polymerase I requires the 5 ' exonuclease Rat1 in yeast}

Aziz El Hage, Michal Koper, Joanna Kufel, et al.

Genes Dev. 2008, 22:

Access the most recent version at doi:10.1101/gad.463708

Supplemental http://genesdev.cshlp.org/content/suppl/2008/03/27/22.8.1069.DC1
Material

References This article cites 46 articles, 28 of which can be accessed free at: http://genesdev.cshlp.org/content/22/8/1069.full.html\#ref-list-1

License Freely available online through the Genes \& Development Open Access option.

Email Alerting Receive free email alerts when new articles cite this article - sign up in the box at the top Service right corner of the article or click here.

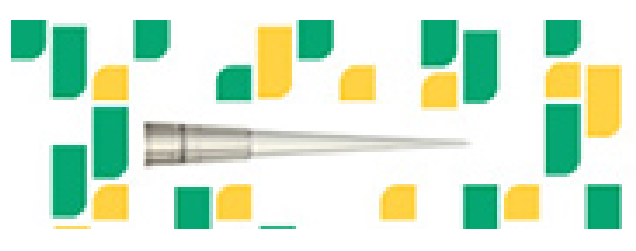

Focused on your science. 